\title{
Challenges and Achievements with Regard to Woman and Child Abuse Prevention by the South African Police Services
}

\author{
Mothibi A Kholofelo \\ Department of Criminology and Criminal Justice, University of Limpopo, South Africa
}

Copyright $(2015$ by authors, all rights reserved. Authors agree that this article remains permanently open access under the terms of the Creative Commons Attribution License 4.0 International License

\begin{abstract}
The purpose of the paper is to explore the South African Police Services (SAPS) measures in fighting against woman and child abuse in South Africa since 1994. The challenges and successes within the campaigns against abuse are also highlighted. Police crime statistics released in September 2012 state that in 2011/2012 there were a total of 9193 sexual offences reported to the SAPS in the Western Cape. The SAPS has recently re-introduced the Family Violence, Child Protection and Sexual Offences (FCS) units throughout the country to ensure that crimes against women and children are adequately addressed by the police. Legislation includes amongst: The Domestic Violence Act 116 of 1998, the Protection from Harassment Act 17 of 2011, and Children's Act No. 38 of 2005. The findings further revealed that the SAPS face challenges when fighting against abuse. Amongst the challenges are the unreported cases of abuse and victims withdrawing their cases because of financial dependency on the offender. Sixteen Days of Activism on No Violence against Women and Children it is a major campaign that is used by SAPS to address abuse. The paper used secondary data, collected from various scholarly documents on woman and child abuse. The paper draws conclusion from the findings obtained in the existing literature and makes recommendations on how SAPS can improve in the prevention of women and child abuse in South Africa.
\end{abstract}

Keywords Domestic Violence, Victimization, Abuse, Sexual Offences, Offender

\section{Introduction}

Violence is widespread in South African society to the extent that the country has been described as having the highest prevalence of violence and violence-related injury in the world among countries where this is measured. South Africa also ranks extremely high internationally for reported incidents of sexual violence. With such high rates of violence occurring in society, United Nations Children's Fund (UNICEF) [1], argues that it is no surprise that violence against children is also common. According to Mathews et al [2] violence and injuries are the second leading causes of death in South Africa, with social factors underpinning the perpetuation of violence. Contributing social drivers of these high levels of violence include factors such as: poverty, patriarchal notions of masculinity, weak parenting and toxic childhoods, alcohol abuse and weakness in the law enforcement system, all resulting in child sexual abuse being a persistent problem.

Globally, estimates show that between $7-37 \%$ of females and $5-10 \%$ of male children have experienced sexual abuse. In South Africa, one in six of all reported chronic sexual abuse cases is a girl under the age of 12 years. The social context of child sexual abuse in South Africa hinges on inequality and patriarchal constructions of masculinities which reinforces male dominance over women and girls, thereby increasing their vulnerability. Mathews [2] further writes that the unequal power relations promote notions of male sexual entitlement and often lead to abuse without fear of its consequences.

According to the Bezuidenhout [3] violence against children often happens within nuclear families, accompanied by domestic violence against the women in the family. Other family members, such as grandparents in particular, have for many decades provided loving care and good socialisation for their grandchildren in the permanent or temporary absence of the children's parents. However, such care is not always adequate. It is especially difficult when the careers are poor, old, and themselves weak and vulnerable and in a situation where social services are non-existent or inadequate.

Children are most at risk of being assaulted by a person known to them. School settings in South Africa, as in many African countries, serve as a particular context in which sexual and physical violence are perpetrated against girls and boys. Although policies are in place to protect children 
against exploitation and punishment, they lack adequate implementation. Furthermore, very little is known about sexual violence against boys and young men. This gap in knowledge needs to be addressed in order to effectively respond to the needs of both boys and girls.

According to the UNICEF [1] violence against women and girls continues to be a global epidemic that kills, tortures, and maims - physically, psychologically, sexually and economically. It is one of the most pervasive of human rights violations, denying women and girl's equality, security, dignity, self-worth, and their right to enjoy fundamental freedoms.

\section{Prevalence of Women and Child Abuse in South Africa}

Studies by Holtmann et al [4] have revealed that in almost $67 \%$ of cases at least some of the variables may be present and the assumptions therefore true. The scale of the problem in South Africa, however, is so big that even if only $33 \%$ of cases involve rape outside of the home or in the public domain, with offenders unknown to the victim, this figure represents more than 15000 reported rapes annually where police action is not hampered by social restraints.

According to Peltzer et al [5] the highest prevalence of domestic violence in South Africa has been reported in the Vhembe district in the Limpopo Province, with 2553 cases in the first quarter of 2012. Peltzer et al [5] further argue that various other studies have described the nature and extent of intimate partner violence in the Vhembe district. Previous studies found a high frequency of intimate partner violence among women with protection orders: with the violence perpetrated reported as physical violence $(96.3 \%)$, sexual violence $(26.5 \%)$ and stalking $(54.0 \%)$,

The UNICEF [1] states that the 2010/11 statistics from the South African Police Service (SAPS) record a total of over 50000 crimes against children for 2010/11. More than half $(52 \%)$ of all reported crimes against children were sexual in nature, while sexual crimes accounted for "only" $19 \%$ of crimes against adult women. Unfortunately, in many case the age of the reported victim is not known. If one accepts the patterns shown where ages are reported, most reported crimes against children are perpetrated against children between the ages of 15 to 17 years (55\% of murders, $60 \%$ of attempted murders, $71 \%$ of assault with grievous bodily harm, $63 \%$ of common assault and $40 \%$ of sexual offences). However, $61 \%$ of the children who endured sexual offences were under the age of 15 years and over quarters (29\%) were between 0 and 10 years.

South Africa's Gauteng Province, statistics show that one in six of all rape cases reported to the police during 2003 is those of girls below the age of 12 years who have been chronically or repeatedly abused. Similarly, in the Eastern Cape, $39.1 \%$ of women and $16.7 \%$ of men report experiencing sexual abuse before the age of 18 . Holtmann et al [4] argue that Gauteng emerges as the province with the largest number of recorded crimes against children, although KwaZulu- Natal has a larger child population. Northern Cape records the highest rate of recorded crime, closely followed by Western Cape and Free State.

\section{Aim}

- To highlight the challenges faced by the SAPS in the prevention of women and child abuse in South Africa.

\section{Objectives}

- To identify the policies developed in the prevention of women and child abuse in South Africa.

- To explore ways in which SAPS tackles women and child abuse.

- To make recommendations on how the SAPS can prevent women and child abuse.

\section{Legislative Framework in the Prevention of Women and Child Abuse in South Africa}

\section{The Domestic Violence Act No 116 of 1998}

According to Davis et al [6] the Domestic Violence Act was formulated with the aim of affording victims of domestic violence the maximum protection from domestic abuse that the law can provide. It recognises that victims of domestic violence are among the most vulnerable members of society and that the remedies available to date had proven to be ineffective. Davis et al [6] further explain that the Act deals with a wide range of behaviour of a controlling or abuse nature that can be defined as domestic violence. The exhaustive list of abuses in section 1 of the act includes physical, sexual, emotional, verbal, psychological and economic abuse, intimidation, harassment, stalking, damage to property, entrance into the victim's without her consent where she is not living with the respondent, and any other controlling behaviour which may cause imminent harm to the safety, health or well-being of the complainant.

The Domestic Violence Act places a duty on any police officer at the scene of a domestic violence incident, or when taking a domestic violence complaint, to render assistance to the victim. Such assistance may, according to Section 2(a), include help in finding suitable shelter and obtaining medical attention. According to the Development Research Africa [7], it is of note that police are on the front line in a fight against domestic violence. In terms of the Domestic Violence Act, there are special duties imposed on members of SAPS to assist complainants. The police are now required to tell women about their rights (preferably in the official language of their choice). In most cases, women who make the effort to report domestic violence to the police receive little guidance about how to resolve the matter via the criminal justice system. The police will also be obliged to help the survivor find a place of safety, obtain medical treatment and accompany the survivor to collect her belongings if 
necessary.

The Domestic Violence Act 116 of 1998 [8] covers a range of violent behaviours, including physical, sexual, emotional, verbal, psychological and economic abuse. In cases of child abuse, family members of a child, children and youth under 21 years of age or any other individual who has a material interest in a child's well-being can apply for protection orders under this Act. Davis et al [6] argue that the protection order grated in terms of the Domestic Violence Act is a civil order. While the protection order prohibits respondents (abusers) from committing certain acts of violence, nowhere does the Domestic Violence Act criminalise domestic violence. It only criminalises the breach of the protection order, and not domestic violence itself. When acts of domestic violence constitute recognised crimes (such as common assault, assault with the intent to do grievous bodily harm, Indecent assault, rape, incest, attempted murder, malicious damage to property ,pointing a firearm) criminal charges can be laid.

\section{Children's Amendment Act No 41 of 2007}

Children's Amendment Act No 41 of 2007 [9] provides the framework for psychological rehabilitative and therapeutic services for abused children, but key to the effectiveness of this legislation is the appropriate resources for the act to be fully implemented safety. According to Matthews et.al [2] further state that due to the nature of child sexual abuse, child protection requires an integrated collaborative response from social services, the police, the courts, medico-legal services, health care services and education, as all these sectors are important in preventing and managing child sexual abuse with the aim of effectively protecting the child. Although child protection is a statutory function, historically, child protection services were primarily delivered by the non-government sector with large gaps in services, particularly in rural areas with shortages of skilled staff and resources. Despite the huge public health burden, services have primarily been focused on statutory processes, with alternative care used as a mechanism to ensure children's safety.

\section{The Sexual Offences Bill}

The Sexual Offences Bill [10] proposes to radically alter both the substance of the common law on rape, as well as numerous procedural and evidentiary aspects of the trail process. Perhaps the most significant recommendation contained in the Bill relates to the definition of rape as conceptualised in the Bill, sexually penetration will now include penetration, to any extent whatsoever, by the genital organs into or beyond the anus, mouth or genital organs of another person, or the penetration of any object including any part of the body into or beyond the anus or genital organs of another person in a manner that simulates sexual intercourse. Davis [6] maintains that the definition of genital organs has been expanded to include the whole or part of male and female genital organs including surgically constructed or reconstructed genital organs.
The Bill also contains an extensive section on the establishment and maintenance of national register for protection of children against sexual offenders. The objective of this provision is to have a record of persons who are found by the court of law not to be suitable to work with children, because they have been convicted of a sexual offence. The purpose of the register is solely to provide, on application, a certificate setting out whether any particular person who intends to work with children has a conviction for sexual offence. The proposed provision is very detailed in setting out who must be included in the register, the contents of the register, the role of the court in managing the information in the register, the removal of the person from the register, and persons entitled to apply for a certificate in respect of information recorded in the register.

\section{Child Justice Act No. 75 of 2008}

Child Justice Act (No. 75 of 2008) [11] aims to protect children who come into contact with the justice and correctional systems. One of the main principles of the Act is to ensure that detention is used only as a last resort in the case of children, with a focus instead on diversion. The Act also sets out specific provisions for the case management of children in the first 48 hours of children coming into contact with the system. UNICEF [1] also states that when a child is detained for a hearing or if court proceedings are postponed, consideration must be given to releasing the child into the care of the parents or guardians. Alternatively, when a decision is made that it is necessary to keep the child detained, the placement of children in detention must be the least restrictive option possible.

In order for diversion to be considered an option, the child has to acknowledge responsibility for the offence and may not be unduly influenced to acknowledge responsibility. A range of diversion options exist and include counselling, an oral or written apology, a compulsory school attendance order, compulsory attendance for educational, vocational or therapeutic purposes, payment of compensation or community service amongst others.

\section{Victim Empowerment Programme}

The Victim Empowerment Programme (VEP), which is led by the Department of Social Development, of which the SAPS is also a key partner, seeks to establish a comprehensive national programme for the provision of services to victims. Frank et al [12] write that this programme prioritises women and children as victims of crime, and the delivery of services to these groups. According to the Development Research Africa [7] the Integrated Victim Empowerment Policy has identified violence against women, child abuse, and domestic violence, victims of sexual assault, abuse of older persons and abuse of people living with disabilities as priority areas. This Policy serves as the framework for service delivery to victims of crime and violence. Victim Empowerment Programme in South Africa commonly assists and empowers youth who are victims of sexual abuse, sexual exploitation and child 
trafficking. Services include trauma counselling, support for reporting the crime to family, police and the court as well as referral support such medical care, shelter and substance abuse counselling, school and community reintegration, empowerment and life skills training.

Development Research Africa [7] further write that the VEP is a major component of the agreement between the Department of Social Development and the United Nations Office for Drug Control and Crime Prevention, for the establishment of one-stop centres for women and children who are victims of abuse, especially domestic violence. Drawing from a pool of expertise and experience in dealing with victims, the department needs to ensure that the policy framework and strategy for shelters for victims of domestic violence is implemented.

\section{Awareness Campaigns}

One of the most common strategies to begin to address violence has been to support and participate in international and national awareness campaigns. The 16 Days of Activism for No Violence against Women and Children is an international campaign which takes place every year from 25 November (International Day for the Elimination of Violence against Women) to 10 December (International Human Rights Day). The period also includes Universal Children's Day and World AIDS Day. In May 2006, government and non-governmental stakeholders developed a plan of action to extend the 16 Days of Activism to 365 days of action.

\section{Methodology}

This study has mainly relied on the review of literature and policies related to the challenges and achievements in the prevention of women and child abuse prevention in South Africa.

\section{The South African Police Services Intervention in Women and Child Abuse}

In 1986, the SAPS established specialised Child Protection Units dedicated to the function of investigating crimes against children. In 1995, a decision was taken to broaden the mandate of these units to operationalise the SAPS policy of prioritising the combating of violence against women and children. Frank et al [12] state that these Units were then renamed the Family Violence, Child Protection and Sexual Offences Units (FCS Units). By 2006, it was reported that there were 49 FCS units in the country as well as 17 units that still operated under the mandate of Child Protection Units. Vetten [13] argues that in 2006 this specialised response suffered a setback when the FCS Units were effectively broken up by disgraced former national Commissioner of Police, Jackie Selebi - only to be restored to full functioning again in April 2011.

According to the UNICEF [13] Family Violence, Child Protection and Sexual Offences Units (FCS) were established to provide crime prevention and victim support services. The FCS units are also responsible for managing reported cases of child abuse, neglect, exploitation and sexual offences. Frank et al [12] state that the FCS Units are complex entities as they respond to several categories of crime, as well as behaviour that are not directly criminalised. The mandate of these units comprises three broad categories, i.e. 1) Family Violence but not including murder; 2) Child Protection, which includes all offences against child victims as well as matters arising from the then Child Care Act 74 of 1983 [14], the Films and Publication Act No 65 of 1996 [15], and the Domestic Violence Act of 1998; and 3) Sexual Offences for all adult victims.

The establishment of victim friendly facilities would be a futile exercise if the police have not been trained on sensitivities to deal with victims of sexual offences. The training programme on First Responders to Sexual Offences continues to equip functional members on how to handle victims, manage the scene of crime and proper recording of sexual offences. The service points where victim friendly services are rendered are located in police stations, satellite police stations, contact points and FCS offices in an attempt to reach out to those in need of this support.

Vetten [16] argues that over the years these early attempts at creating specialised police facilities for women and children have been transformed into Victim Empowerment Centres (VEC) dealing with victims of crime generally (although the police often emphasise their use in relation to crimes against women and children). What has been the SAPS' primary response to sexual offences have been the specialised FCS Units. Vetten [16] further states that by 2012, 2155 FCS detectives had been placed at all 176 policing clusters in the country and a budget of R49.5 million shared between the provinces to ensure the adequate resourcing of the Units . Important as these steps are, they do not add up as yet to a comprehensive policing response to sexual crimes.

\section{Challenges in Dealing with Women and Child Abuse}

Firstly, for virtually all forms of violence, if violence is recognised even by most perpetrators as a negative phenomenon it will be "hidden" wherever possible, and under-reported. Alternatively, if certain forms of violence are not seen as problematic, people will not see the need to report it. Secondly, violence against children often occurs in private settings, and in particular in the home of the child. According to the South African Police Services [17] it is therefore not publicly visible and again is likely to be unreported or under-reported. Thirdly, the fact that the victims are children means that they have less "voice" than adults, are likely to be uninformed about their rights, might not recognise that violence is wrong, and - if they recognise 
it is wrong - might be fearful of reporting it when the perpetrator is in a position of authority or if they fear they may be blamed. Again, this will result in under-reporting.

The other common statement by SAPS regarding (particularly) rape and child abuse is that these crimes typically occur behind closed doors within families, where the offender is known to the victim. As a result the police have no access to prevention mechanisms, cannot reduce rape, cannot dramatically increase reporting rates, and are often hampered in their investigation of the case. They say that the victim is often dependent on the offender for subsistence and is thus unlikely to report the incident, or having reported it, Holtmann et al [4] argue it is more likely to withdraw cooperation before the case is properly investigated or prosecuted.

Vetten [16] states that a national study found that only one in nine women reported being raped to the police, while a more recent Gauteng-specific study found only one in eleven women to have reported to the police. This problem of extensive underreporting is not solved by the creation of specialized units alone. Indeed the current policy of reducing the reporting of crimes like rape by $4-7 \%$ annually is very likely to exacerbate the problem of under-reporting. As it is, this target has introduced perverse incentives into the SAPS to dump dockets, or refuse to accept complaints.

Holtmann et al [4] argue that interpersonal crimes, such as domestic violence, are believed to be less well reported and sexual offences the least well reported. In this last case, a combination of reasons is given: women have little confidence that their complaint will be properly addressed or result in a conviction, and they experience resistance from service providers who display negative attitudes towards them and they doubt they will be believed. Reporting often compounds the trauma and involves an invasive and unpleasant investigation. Sometimes the victim is unaware that what has occurred is an offence and does not know that she has a right to assistance.

\section{Conclusions}

The introduction of the DVA Act 116 of 1998, Children's Amendment Act 41 of 2007 amongst others has marked a milestone in the SAPS's effort to preventing women and child abuse. Family Violence, Child Protection and Sexual Offences Units (FCS) were established to provide crime prevention and victim support services. Eventhough the FCS Units have been restored to fully function again in April 2011the SAPS is still experiencing challenges in dealing with women and child abuse in South Africa. The major gap identified in the literature is that FCS Units only focuses on reported cases of women and child abuse than prevention measures of abuse which will help to avoid the negative consequences of abuse on women and children in South Africa. The SAPS needs further constant training in preventing women and child abuse in South Africa.

\section{Recommendations}

- South African Police Service (SAPS) needs to broaden the Family Violence, Child Protection and Sexual Offences Units (FCS Units) which deals with sexual offences by training more police officers on how to handle sexual offence cases.

- The FCS Units should also focus more on prevention measures of women and child abuse than only dealing with reported cases of abuse.

- The SAPS must focus more on partnership with other organizations and government departments especial the Department of Social Development on identifying women and children who are more at risk of abuse in order to prevent the abuse at an early stage.

- Apart from the 16 Days of Activism for No Violence against Women and Children the SAPS needs to establish more awareness campaigns in which they will educate women and children more about FCS Units, abuse and their rights, including the process involve in when reporting a case of abuse.

- The SAPS needs to establish neighborhood watch in the community where community members can be encouraged to report any incidents of women and child abuse or suspicions of abuse in the community.

- The South African government needs to allocate more budget on Victim Empowerment Programmes so that more victims of abuse who are dependent on the abusers, to be equipped and trained in order for them to be independent economically.

- The FCS Units members needs to improve their services to victims of abuse in order to deal with the unreported cases of abuse because more victims will be encouraged to report if they see that other victims get help.

- The SAPS must make sure that every in police station in South Africa; FCS Units are established and effective.

\section{REFERENCES}

[1] United Nations Children's Fund. Domestic Violence against Women and Girls; 2000. Available at $<$ www.unicef-irc.org/publications/pdf/digest6e.pdf. $>$

[2] Mathews S, Loots L, Sikweyiya. Y, Jewkes. R 2009. Sexual Abuse; 2009. Available from: www.mrc.ac.za/crime/Chapter 7.pdf.

[3] Bezuidenhout C. Child and Youth Misbehaviour in South Africa: A holistic Approach. 2nd ed. Pretoria: Van Schaik Publishers; 2008.

[4] Holtmann L, Swarts L. Current Trends and Responses to Crime in South Africa; 2004. Available from: www.mrc.ac.za/crime/2ndreviewchapter6.pdf.

[5] Peltzer K, Pengpid S. The severity of violence against women 
by intimate partners and associations with perpetrator alcohol and drug use in the Vhembe district, South Africa. African Safety Promotion Journal, 2013; 11 (1):15-28.

[6] Davis L, Snyman R. Victimology in South African. Pretoria: Van Schaik.; 2005.

[7] Development Research Africa. Consolidated Report on the Nature and Prevalence of Domestic Violence in South Africa; 2008. Available from:www.cindi.org.za/.../Consolidated_Re port_Domestic_Violence_South\%2.

[8] Domestic Violence Act, No 116 of 1998, [cited 2012 Jun 11]. Available from:http://www.justice.gov.za/legislation/acts/19 98-116.pdf.

[9] Children's Amendment Act 41 of 2007, [cited 2013 May 4]. Available from:http://web.up.ac.za/sitefiles/43/childrenAme ndment41.pdf.

[10] Sexual Offences Bill. Sexual Offences and Related Matters. Pretoria: Government Printers; 2012.

[11] Child Justice Act No 75 of 2008, [cited 2013 Feb 14]. Available from:http://www.justice.gov.za/legislation/acts/20 08-075_childjustice.pdf.
[12] Frank C, Waterhouse S, Griggs R, Rontsch R. Raising the Bar: A review of the restructuring of the SAPS Family Violence, Child Protection and Sexual Offences Unit; 2008. Available from:www.rapcan.org.za/File_uploads/Resources/FCS_repo rt_text_web1.pdf.

[13] United Nations Children's Fund. Violence against Children in South Africa; 2012.www.cjcp.org.za/uploads/2/7/8/4/.../vac _final_summary_low_res.pdf.

[14] Child Care Act No 74 of 1983, [cited 2013 May 12]. Available from:http://www.dsd.gov.za/dmdocuments/Child Care_Act.pdf.

[15] Film and Publication Act No 65 of 1996, [cited 2013 May 15]. Available from:http://www.fpb.org.za/legislation/.../293-fil ms-and-publications-act-no-65.

[16] Vetten M. Will any police officer do? The organisation of the South African Police Service's (SAPS) response to sexual offences; 2012. Available from: http://www.tlac.org.za/wp-c ontent/uploads/2012/01/TLAC-Policy-Brief4.SAPSresponse to sexual offence.pdf

[17] South African Police Services. 2012/13 Annual Report. Pretoria: Government Printers; 2013. 